\title{
Not just any old pile of dirt: evaluating the use of artificial nesting mounds as conservation tools for freshwater turtles
}

\author{
James E. Paterson, Brad D. Steinberg and Jacqueline D. Litzgus
}

\begin{abstract}
The viability of freshwater turtle populations is largely dependent on the survivorship of reproducing females but females are frequently killed on roads as they move to nesting sites. Installing artificial nesting mounds may increase recruitment and decrease the risk of mortality for gravid females by enticing them to nest closer to aquatic habitats. We evaluated the effectiveness of artificial nesting mounds installed in Algonquin Park, Canada. Artificial mounds were monitored for 2 years to determine if turtles would select them for nest sites. We also simulated turtle paths from wetlands to nests to determine the probability that females would encounter the new habitat. A transplant experiment with clutches of Chrysemys picta and Chelydra serpentina eggs compared nest success and incubation conditions in the absence of predation between artificial mounds and natural sites. More turtles than expected used the artificial mounds, although mounds comprised a small proportion of the available nesting habitat and the simulations predicted that the probability of females encountering mounds was low. Hatching success was higher in nests transplanted to artificial mounds (93\%) than in natural nests (56\%), despite no differences in heat units. Greater use than expected, high hatching success, and healthy hatchlings emerging from nests in artificial mounds suggest promise for their use as conservation tools.
\end{abstract}

Keywords Artificial nesting mound, egg transplant, fitness, freshwater turtle, heat units, nest-site selection

\section{Introduction}

$\mathrm{W}$ orldwide, freshwater turtle populations are undergoing severe declines from habitat loss, collection, and additive mortality of adults (Gibbons et al., 2000). In temperate North America extensive road networks cause excessive mortality of adult turtles and pose barriers for

James E. Paterson and Jacqueline D. Litzgus (Corresponding author) Department of Biology, Laurentian University, 935 Ramsey Lake Road, Sudbury, Ontario P3E 2C6, Canada. E-mail jlitzgus@laurentian.ca

Brad D. SteInberg Ontario Ministry of Natural Resources, Algonquin Provincial Park, Ontario, Canada

Received 29 February 2012. Revision requested 10 May 2012.

Accepted 6 June 2012. First published online 12 September 2013. movement between wetlands and nesting areas (Steen et al., 2006). Large terrestrial forays by female turtles (Steen et al., 2012) are important to locate appropriate nesting sites but expose them to an increased risk of mortality on roads (Haxton, 2000; Gibbs \& Shriver, 2002; Steen et al., 2006). This mortality has demographic consequences including decreased population sizes and recruitment rates, and skewed sex ratios (Marchand \& Litvaitis, 2004a; Aresco, 2005). Unpaved roads and roadside shoulders may attract nesting female turtles (Steen et al., 2006) and these sites not only present a mortality risk, they may also reduce nesting success through compaction of soil (inhibiting emerging hatchlings or crushing eggs), pollution, and road mortality of emerging hatchlings (Aresco, 2005).

Artificial nesting mounds have been suggested as a conservation tool to reduce adult turtle mortality on roads and increase recruitment (Kiviat et al., 2000; Marchand \& Litvaitis, 2004b; Beaudry et al., 2010). By placing mounds that can successfully incubate eggs in close proximity to aquatic habitats used by turtles, migrations to nesting sites will be shorter and will reduce the risk of adult females being killed on roads. In addition, increasing the number and/or quality of nesting sites may increase recruitment in degraded or fragmented habitat if hatching success is equal to or greater than at natural nesting sites. Nest-site characteristics and location have important implications for recruitment and affect hatching success (Wilson, 1998; Kolbe \& Janzen, 2002a), predation risk to the female and nest (Temple, 1987; Spencer, 2002; Spencer \& Thompson, 2003), and the fitness of hatchlings (O'Steen, 1998; Kolbe \& Janzen, 2001, 2002b). Although the successful use of artificial nesting sites has been noted previously (Dowling et al., 2010; Buhlmann \& Osborn, 2011), ours is the first study to evaluate their efficiency by comparing mound use and nest success to natural nest sites. The objective of our study was to evaluate quantitatively the use of artificial nesting mounds as a conservation tool for freshwater turtles. We based our evaluation on five criteria, and deemed the artificial mounds to be successful if (1) turtles encountered and used the artificial mounds, (2) hatching success was equal to or higher at artificial sites vs natural sites, (3) the fitness of hatchlings from artificial mounds was equal to or higher than that of hatchlings from natural nests, (4) incubation conditions were similar in artificial and natural sites, and (5) emergence dates and incubation durations were similar at artificial and natural sites. 


\section{Study area}

The study site is in Algonquin Provincial Park, Ontario, Canada. We withhold the specific locations, to prevent illegal collection. The area is relatively undisturbed and consists of a mosaic of wetlands, rivers, and lakes in an upland pine forest accessible by logging roads. The study area was c. 2,000 ha and is home to four species of freshwater turtles: Blanding's turtles Emydoidea blandingii, painted turtles Chrysemys picta, snapping turtles Chelydra serpentina, and wood turtles Glyptemys insculpta. C. picta and $C$. serpentina are relatively abundant at the study site but $E$. blandingii and $G$. insculpta use only specialized habitats (Compton et al., 2002; Edge et al., 2010), occur at low densities, and are categorized as Endangered on the IUCN Red List (IUCN, 2011).

\section{Methods}

\section{Artificial nesting mounds}

Four artificial nesting mounds were installed on 30 April 2009. The substrate was a mixture of granular A gravel $(60 \%)$ and sand $(40 \%)$, to imitate the consistency of nesting sites favoured by turtles. A layer of geotextile cloth was placed underneath mounds to prevent growth of vegetation. Each mound was approximately circular with a $3 \mathrm{~m}$ radius and standing $0.5 \mathrm{~m}$ high with a south-west facing slope. Locations were selected based on previous observations of turtles nesting and the perceived risk of road mortality. Each mound was placed within $100 \mathrm{~m}$ of an aquatic habitat and within $50 \mathrm{~m}$ of known nesting sites. Mounds were at least $1.5 \mathrm{~km}$ apart, and no females switched nesting sites during the study (four independent groups of nesting turtles).

\section{Nest monitoring}

Artificial mounds, known natural nesting sites, and potential nesting sites within $1 \mathrm{~km}$ of artificial mounds were monitored each night (17.00-24.00), on foot, during the nesting seasons of 2009 (27 May-26 June) and 2010 (19 May-16 June) by teams of 2-4 researchers. This time was chosen because the majority of nesting behaviour for the study species occurs in the late afternoon or evening (Christens \& Bider, 1987; Congdon et al., 1987; Standing et al., 1999; Walde et al., 2007). Sites were also monitored opportunistically at dawn for nesting C. serpentina. Nests were excavated within the first 24 hours after oviposition (Samson et al., 2007) to determine clutch size, maximum nest width, and maximum nest depth $(\mathrm{cm})$. Eggs were returned to the nest chamber in the same orientation as found.
Encounter rate and use of artificial nesting sites (criterion 1)

All known natural nesting sites and the artificial nesting mounds were monitored, as described above, to determine their extent of use. The locations of nests were recorded with a global positioning system (GPS).

Based on their availability as potential nesting habitat, we estimated how many nests were expected to be in artificial nesting mounds. Using ArcGIS v. 9.2 (ESRI, Redlands, USA) potential nesting habitat, which was restricted to areas with open canopy and low ground cover, was mapped within $500 \mathrm{~m}$ of a wetland at each site. We then calculated the proportion of nesting habitat at each site covered by artificial nesting mounds. Mounds were assumed to be perfect circles with a radius of $3 \mathrm{~m}$ (i.e. an area of $28.26 \mathrm{~m}^{2}$ ). If the artificial mounds were preferred equally to natural sites then the proportion of nests in artificial mounds would be proportional to the amount of available nesting habitat they comprised.

To test the likelihood of females encountering artificial mounds while searching for nest sites, we modelled their paths from the nearest aquatic habitat to actual nest locations using correlated random walks in Hawth's Tools (Beyer, 2004) for ArcGIS. This was done at two sites (Sites 1 and 2; Fig. 1) that each had $>20$ natural nests (any turtle species) combined over the two field seasons. The other sites had low densities of nests and were excluded from these analyses. Although nest-site selection is not random, correlated random walk models may appropriately represent likely paths used by nest-searching females because they are biased in one direction but allow random deviations in angles and path length to occur from aquatic habitat to nest sites. The parameters used in the model were based on Bowne \& White's (2004) observations of terrestrial movements by homing C. picta. We assumed that turtles moved overland at a mean speed of $1 \mathrm{~m}$ per minute. Every path used a maximum of 40 steps that each represented a 10 minute period (maximum 400 minutes nesting foray) and had a mean length of $10 \pm \mathrm{SD} 4.8 \mathrm{~m}$. Because turtles moving through terrestrial habitats to nesting sites tend to travel in a relatively straight line (Graham et al., 1996; Caldwell \& Nams, 2006) we used a mean turning angle of $0 \pm \mathrm{SD} 12^{\circ}$. For each nest 100 paths were simulated from water to that nest. The encounter rate with artificial nesting mounds was estimated using the mean number of paths per nest that crossed the mound. A kernel density estimate of paths was generated using $\operatorname{ArcGIS}$, to determine where path densities were highest; locations with higher path densities would intercept more nesting females.

\section{Transplant experiment (criteria $2-5$ )}

Differences in recruitment success and incubation environments between nests on artificial mounds and natural nests 

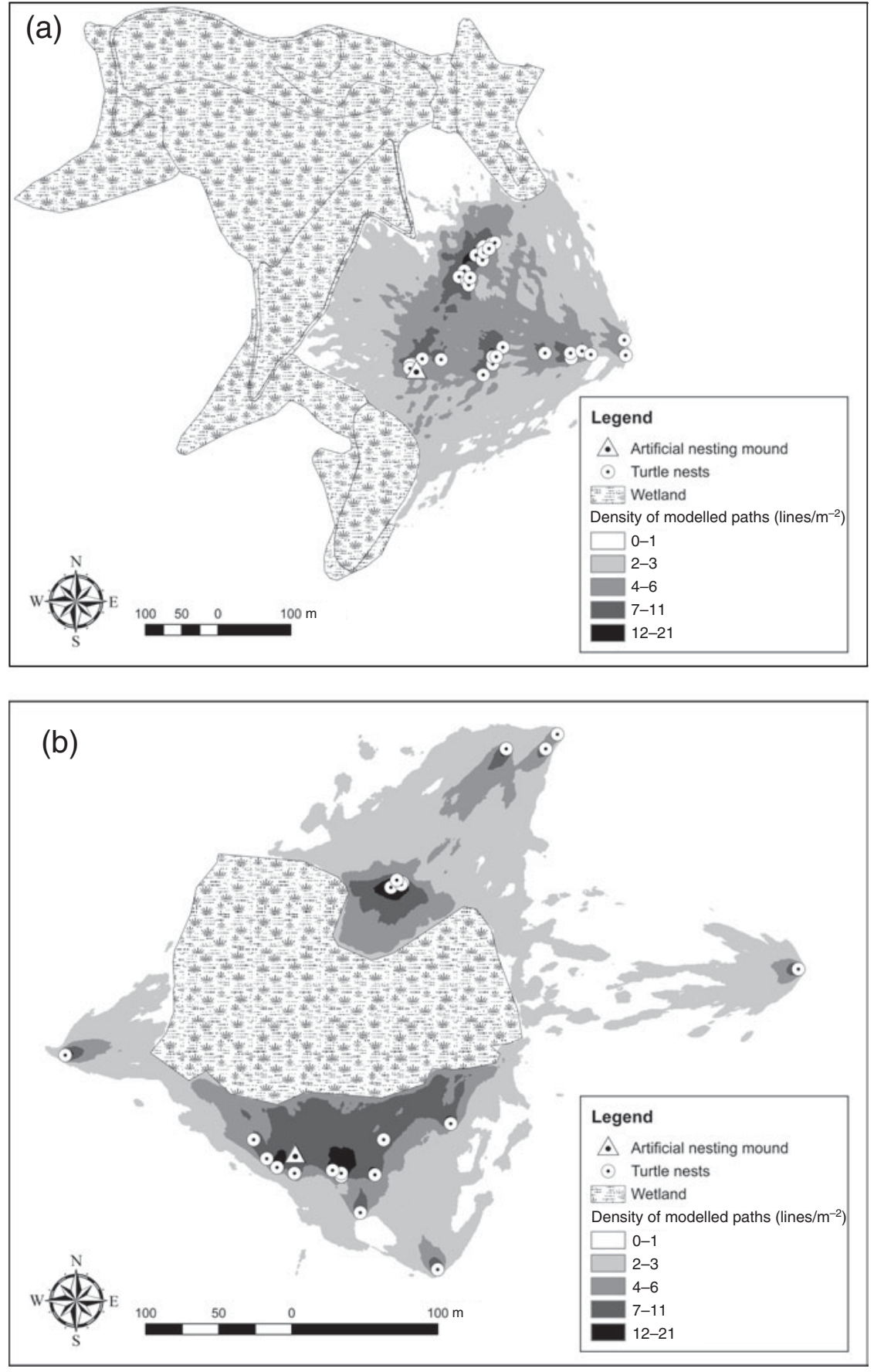

FIG. 1 The path density of modelled paths of turtles from wetlands to nests at (a) Site $1(\mathrm{n}=31$ nests $)$, and (b) Site $2(\mathrm{n}=21$ nests) in relation to artificial nesting mounds ( $\mathrm{n}=1$ at each site). Each nest had 100 paths constructed using correlated random walk paths (see text for details). were measured using a transplant experiment during 2010. Clutches of C. serpentina $(\mathrm{n}=12)$ and C. picta $(\mathrm{n}=9)$ were divided equally to control for maternal effects: half the eggs were incubated in the natural nest cavity, and half were transferred to the closest artificial mound. The clutch sizes, nest depths and incubation requirements of these two species are varied and encompass the requirements of the other two species at the site (E. blandingii and G. insculpta). All eggs (natural and transplants) were removed from the original cavity and transported in the same container to remove the effect of transport on hatching success. All eggs were placed in nest cavities (natural or transplant) in the same orientation in which they were found. Eggs transferred to artificial mounds were placed in a cavity the same width and depth as the natural nest. A predator exclusion cage was buried over the top and down the sides of all nests to prevent predation of the eggs. The predator exclusion cage was made of $2.5 \mathrm{~cm}$ grid hardware cloth and the design was uniform across both treatments so that any minor effects on microclimate were equal for both groups. Although differences in nest predation between natural and artificial nesting sites should be addressed, the goal of our study was to determine 
if hatching success and incubation conditions were similar between treatment groups. Natural nest predation rates are often high, and predators were excluded to avoid the loss of replicates. C. picta clutches with 10 or more eggs were used to ensure a sufficient number of eggs in each treatment.

Beginning in early August nests were checked daily for emerging hatchlings. Carapace length was measured to the nearest $0.01 \mathrm{~cm}$ using callipers and mass $( \pm 0.1 \mathrm{~g})$ was measured using Pesola spring scales. In October, nests with hatchlings that did not emerge were excavated to determine the fate of the remaining embryos. Hatching success (arcsine-square-root transformed to normalize) of C. picta and $C$. serpentina nests transplanted to artificial mounds were compared to nests at natural sites using a paired $t$-test to control for maternity, with both species pooled together because they were being used to test the same hypothesis regarding hatching success. The hatching success of a nest was the proportion of fertilized eggs that pipped successfully.

The fitness of emerging hatchlings was estimated through proxies: body condition and deformities. Body condition refers to the relative amount of fat and water stored in an organism (Jakob et al., 1996; Litzgus et al., 2008). Mixed-effects linear models were used to test the effect of nest treatment (natural or transplanted to artificial mound) on hatchling mass using carapace length as a covariate and clutch as a random effect. This test compared body condition between treatments using a size corrected mass (Garcia-Berthou, 2001). We compared the rates of deformities in clutches of both species between natural nests and those transplanted to artificial mounds, using a two-way ANOVA. A hatchling was considered to have a deformity if the pattern of scutes on the carapace or plastron deviated from the normal complement (Ernst \& Lovich, 2009). Colour variations were not considered deformities.

Physical characteristics were measured at natural nesting sites and on artificial mounds to compare incubation conditions between treatments. A temperature datalogger (iButton, Maxim, Sunnydale, USA) in the centre of each nest recorded hourly temperature $\left( \pm 0.5^{\circ} \mathrm{C}\right)$. Heat unit accumulation is used to predict the outcome of a biological process (Arnold, 1960; i.e. embryological development in our case) and is expressed in degree days (Bakersville \& Emin, 1969). The total heat units above a threshold temperature of $20^{\circ} \mathrm{C}$ accumulated hourly were calculated for each nest. Below this temperature, embryos survive but do not develop (Schwarzkopf \& Brooks, 1987). Total heat units for a nest were calculated from the day after eggs were laid until the day hatchlings emerged from that nest. If no hatchlings emerged, heat units were calculated until the last day a hatchling naturally emerged at any site (13 September for C. picta, 30 September for C. serpentina). The hydric environment of a nest affects nest success and hatchling body size (Packard et al., 1987; Janzen et al., 1995, 2000), therefore percentage soil moisture was measured in all nests on 15 July 2010 (after the nesting season) using a HydroSense soil moisture probe (Campbell Scientific, Edmonton, Canada). Overstorey canopy cover (\%) was measured at all nests using a densiometer, on 15 July 2010. Soil moisture (\%, log transformed), overstorey canopy cover (\%), and total heat units (degree days), were compared between natural nests and nests transplanted to artificial mounds using two-way ANOVAs with species and treatment as predictor variables. Relationships between heat units and soil moisture were tested using linear regressions for each species.

To determine whether clutches in one treatment group emerged earlier, the time (days, log transformed) from oviposition to the first emergence was compared between treatments using a two-way ANOVA with species and treatment as predictor variables.

\section{Results}

Encounter rate and use of artificial nesting sites (criterion 1)

Over the two nesting seasons four turtles nested on the artificial mounds. In 2009 one C. picta and one C. serpentina nested on the same mound. In 2010 two E. blandingii nested on artificial mounds. All of these nests had $100 \%$ hatching success. In addition, five other turtles were observed testpitting (a nest-searching behaviour) on three out of four mounds in 2010. G. insculpta was the only species that was not observed on artificial nesting mounds in either year. The mean proportion of nests that were in artificial mounds (3.8\% \pm SE 2.8$)$ was higher than expected $(1.7 \% \pm$ SE 1.7$)$ based on the mean proportion of available nesting habitat in artificial mounds.

The probability that females would encounter artificial nesting mounds was low. The mean probability of a turtle's path intercepting the artificial mound at Site 1 was $2.6 \% \pm$ SE 0.8 . The kernel density estimator showed that although the mound would probably intercept some females (4-6 paths $\mathrm{m}^{-2}$ ), encounter rate could have been increased to $7-11$ paths $\mathrm{m}^{-2}$ by placing it on the north side of the site (Fig. 1a). The mean probability of a turtle's path intercepting the artificial mound at Site 2 was $5.8 \% \pm$ SE 2.7. The kernel density estimator showed that the artificial nesting mound was in a location that would probably intercept close to the maximum possible number of nesting turtles (7-11 paths $\mathrm{m}^{-2}$; Fig. 1b).

\section{Transplant experiment (criteria $2-5)$}

Hatching success was high overall among nests of both C. picta and C. serpentina (Table 1). Hatching success, 
TABLE 1 Mean \pm SE measurements of variables in Chrysemys picta $(\mathrm{n}=9)$ and Chelydra serpentina $(\mathrm{n}=12)$ nests that incubated in sites chosen by females (Natural) and in those transplanted to artificial nesting mounds (Transplant). Probabilities from two-way ANOVAs are given for each variable, except hatching success for which the probability is from a paired $t$-test with species pooled (see text for details). Statistically significant probabilities are in bold.

\begin{tabular}{|c|c|c|c|c|c|c|}
\hline \multirow[b]{2}{*}{ Variable } & \multicolumn{2}{|l|}{ Chrysemys picta } & \multicolumn{2}{|c|}{ Chelydra serpentina } & \multicolumn{2}{|l|}{$\mathrm{P}$} \\
\hline & Natural $(\mathrm{n}=9)$ & Transplant $(\mathrm{n}=9)$ & Natural $(\mathrm{n}=12)$ & Transplant $(\mathrm{n}=12)$ & Treatment & Species \\
\hline Heat units & $244 \pm 22$ & $272 \pm 7.5$ & $232 \pm 22$ & $225 \pm 12$ & 0.63 & 0.10 \\
\hline Canopy cover (\%) & $4.6 \pm 2.6$ & $8.9 \pm 2.3$ & $2.4 \pm 1.3$ & $4.3 \pm 1.8$ & 0.14 & 0.10 \\
\hline Moisture (\%) & $5.9 \pm 0.8$ & $4.8 \pm 0.2$ & $7.5 \pm 0.9$ & $6.0 \pm 0.9$ & 0.04 & 0.06 \\
\hline Days to emergence & $98 \pm 7.2$ & $104 \pm 4.7$ & $101 \pm 4.0$ & $98 \pm 1.9$ & 0.74 & 0.89 \\
\hline Hatching success & $71 \pm 14$ & $98 \pm 2$ & $56 \pm 11$ & $88 \pm 3.4$ & 0.02 & \\
\hline
\end{tabular}
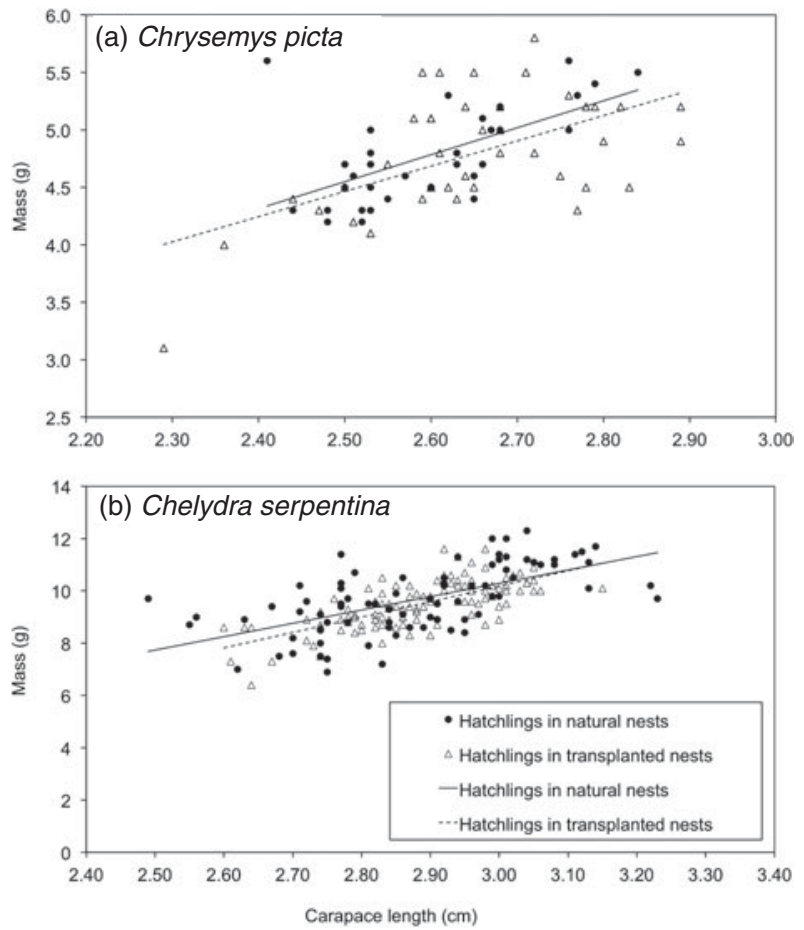

FIG. 2 Body condition of (a) Chrysemys picta $(\mathrm{n}=74)$, and (b) Chelydra serpentina $(\mathrm{n}=193)$ hatchlings emerging from natural nests and artificial nesting mounds in the transplant experiment, in 2010. There was no difference in body condition between the two treatments for either species (see text for details).

in the absence of predation, was higher in nests on artificial nesting mounds (mean $=93 \%$ ) than in natural nests $($ mean $=56 \% ; t=2.74, \mathrm{df}=20, \mathrm{P}<0.02)$.

A total of 74 C. picta hatchlings (33 from natural nests, 41 from artificial mounds) and 193 C. serpentina hatchlings (83 from natural nests, 110 from artificial mounds) were used for analyses of body condition. Size-adjusted masses of C. picta hatchlings from nests on artificial mounds were not different from those of hatchlings from natural nests $(F=1.34, \mathrm{df}=1,62, \mathrm{P}=0.19$; Fig. 2a). Size-corrected hatchling mass of $C$. serpentina did not differ between treatment groups $(F=1.05, \mathrm{df}=1,180, \mathrm{P}=0.29$; Fig. $2 \mathrm{~b})$. There was
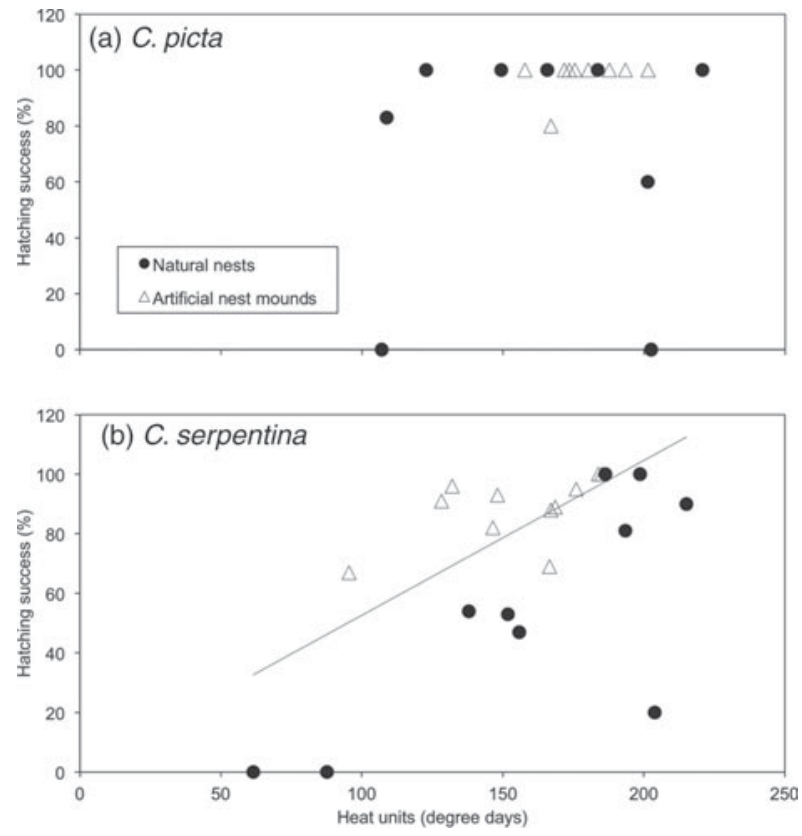

FIG. 3 Relationship between hatching success and accumulated heat units for nests of (a) C. picta, and (b) C. serpentina in the transplant experiment, in 2010.

a higher rate of scute deformities in C. picta than in C. serpentina $(F=8.30, \mathrm{df}=1,28, \mathrm{P}<0.01)$ but deformity rates did not differ between treatments $(F=1.98, \mathrm{df}=1,28$, $\mathrm{P}=0.17)$. The interaction between deformity rate and species was not significant $(F=0.08, \mathrm{df}=1,28, \mathrm{P}=0.78)$.

Physical conditions of natural nests vs those transplanted to artificial mounds are summarized in Table 1. Heat units accumulated during incubation did not differ between natural and artificial sites $(F=0.24, \mathrm{df}=1,36, \mathrm{P}=0.63)$, or between species $(F=2.84, \mathrm{df}=1,36, \mathrm{P}=0.10)$. Moisture in nests differed between artificial mounds and natural nests $(F=5.48, \mathrm{df}=1,36, \mathrm{P}=0.04)$ but not between species $(F=3.63, \mathrm{df}=1,36, \mathrm{P}=0.06)$. Overstorey canopy cover of nests did not differ between treatments $(F=2.30, \mathrm{df}=1,36$, $\mathrm{P}=0.14)$ or between species $(F=2.86, \mathrm{df}=1,36, \mathrm{P}=0.10)$. Hatching success was not related to heat units in $C$. picta nests $(F=0.69$, df $=1,16, \mathrm{P}=0.42$; Fig. $3 \mathrm{a})$ but increased 
linearly with heat units in C. serpentina nests $(F=13.72$, $\mathrm{df}=1,22, \mathrm{P}<0.01$; Fig. 3 b). Soil moisture was not related to hatching success in C. picta $(F=0.90, \mathrm{df}=1,16, \mathrm{P}=0.77)$ or C. serpentina $(F=0.60, \mathrm{df}=1,22, \mathrm{P}=0.45)$.

Hatchlings began emerging earlier from natural nests (12 August and 28 August for C. picta and C. serpentina, respectively) than from nests on artificial mounds (29 August and 2 September for C. picta and C. serpentina, respectively). However, time from oviposition to first emergence (days, log transformed) did not differ between natural and artificial sites $(F=0.11, \mathrm{df}=1,19, \mathrm{P}=0.74)$ or between species $(F=0.02, \mathrm{df}=1,19, \mathrm{P}=0.89)$.

\section{Discussion}

Although we observed few nests in artificial sites, more turtles used mounds than expected based on their availability. Nesting habitat was readily available at the site but artificial mounds may have higher use and effectiveness in degraded systems with low availability of nesting sites. In addition to the fact that artificial mounds constituted only a small fraction of available nesting habitat, low rates of mound use may have also occurred because (1) the mounds were not attractive habitat for nesting turtles, (2) only small numbers of females have so far encountered them, or (3) nest-site fidelity reduced the likelihood that turtles would switch nest locations.

Mounds appear to have provided attractive habitat for nesting turtles. The transplant experiment revealed similar environmental conditions (e.g. temperature, canopy cover) in artificial mounds vs natural nests for variables that turtles may use to select nesting sites (Morjan \& Valenzuela, 2001; Spencer, 2002). In contrast, the simulations of turtle paths to nests suggest that there was a low probability that turtles would encounter sites, probably because they constituted a small fraction of the available habitat. If few turtles have so far encountered mounds but they are suitable nesting habitat, then mound use should increase over time and this should be monitored.

Another factor that may reduce use of artificial nesting mounds is nest-site fidelity, which is common in freshwater turtles (Freedberg et al., 2005; Rowe et al., 2005). Females may be unlikely to switch nesting sites even if alternate habitat is suitable and readily available. However, many species demonstrate flexibility in nest-site selection (Schwarzkopf \& Brooks, 1987; Spencer \& Thompson, 2003) and some species, such as spotted turtles Clemmys guttata, show fidelity to substrate type rather than geographical location (Rasmussen \& Litzgus, 2010). Therefore, artificial nesting sites may still attract females if they previously nested on similar substrate types (e.g. road-side shoulders, open fields, gravel pits, beaches). In addition, turtles often use nesting sites that are of recent anthropogenic origin
(Beaudry et al., 2010); this indicates that females can switch nesting sites when suitable habitat is created.

An important consideration for the use of nesting mounds as a conservation tool is the predation rate on nests. Predation rates on freshwater turtle nests are typically high (Congdon et al., 1987; Spencer, 2002; Marchand \& Litvaitis, 2004b) and a limitation of our study is that we did not address whether nest predation rates differed on artificial mounds vs natural nesting sites because all nests had predator exclusion cages. Artificial mounds, which could have high densities of nests in degraded habitats, may attract predators and act as population sinks for turtles (Burke et al., 1998; Doody et al., 2003; Marchand \& Litvaitis, 2004 b). Predation rates may also vary by mound location and thus placement of mounds should incorporate other landscape features that may reduce predation, such as being placed away from habitat edges (Temple, 1987; Kolbe \& Janzen, 2002c; Marchand \& Litvaitis, 2004b). Future work should compare predation rates on artificial nesting mounds vs natural nests at the same site.

Hatching success of eggs transplanted to artificial nesting mounds was significantly higher than that of eggs in natural nests, indicating that artificial mounds have the potential to improve recruitment. Although there were no differences in heat units, moisture levels were significantly lower in artificial mounds. However, the difference in moisture between treatments $($ mean $=1.4 \%)$ probably does not represent a biologically relevant difference for females selecting nest sites. It is possible the difference in moisture arose because the artificial mounds had looser soil than natural sites, although they retained their shape and profile throughout the two seasons. Artificial nesting mounds successfully incubated turtle eggs at biologically relevant depths and conditions that were similar to natural nests.

There was no difference in body condition between hatchlings from natural nests and those from eggs transplanted to artificial mounds. Because nest moisture and maternal effects are probably the most important factors determining hatchling size (Packard et al., 1987; Janzen et al., 1995), the lack of difference in hatchling body condition observed in our study also suggests that the small difference in hydric conditions between treatments may not be biologically relevant. In addition, there was no difference in deformity rate between treatments. Environmental and genetic factors were similar between treatments, and these factors are the largest sources of deformities in hatchlings (Gutzke et al., 1987; Steyermark \& Spotila, 2001; de Solla et al., 2008).

Thermal conditions in nests transplanted to artificial mounds were similar to those in nest sites chosen by turtles, suggesting that cues used by turtles to select nesting sites could promote the use of artificial mounds and that these nests will experience similar success to natural nests, if not higher. The thermal regime in a nest has strong 
conservation implications for turtle species with temperature-dependent sex determination (Ewert \& Nelson, 1991). The lack of a relationship in C. picta nests between hatching success and heat units suggests that all nests of both treatments received sufficient heat units to complete development. In contrast, the heat units accumulated by C. serpentina nests limited hatching success. C. picta nested earlier in the season (first nest 19 May 2010) and had shallower nests than those of $C$. serpentina (first nest 28 May 2010). Heat unit accumulation at nesting sites may be limiting for C. serpentina, which in most years do not successfully develop and emerge in Algonquin Park because of the short summer season (Obbard \& Brooks, 1981; R.J. Brooks pers. comm.).

Hatchlings emerged from natural nests and nests transplanted to artificial mounds after a similar number of days. Hatchlings emerging from nests in artificial mounds would therefore experience similar environmental stresses and predation levels as those emerging from natural nests. Differences in emergence timing could affect mortality rates of hatchlings from predators and from environmental factors such as sub-freezing autumn temperatures (Obbard \& Brooks, 1981; Draud et al., 2004). The success of artificial nesting mounds relies not only on the successful incubation of embryos but also on the success of emerging juveniles in being recruited into the population. The lack of difference in incubation duration further supports the appropriateness of artificial nesting mounds as a conservation tool.

We observed low but nonetheless higher than expected use of artificial nesting mounds based on their availability, and the incubation conditions at artificial mounds were similar to those observed at natural nests. Sufficient heat units were accumulated to allow development of turtle embryos at biologically relevant depths and hatchlings emerged naturally on similar dates to natural nests. In addition, higher hatching success at artificial sites vs natural nests indicates that the creation of additional nesting habitat for turtles may increase recruitment. The placement of mounds will probably intercept female turtles moving to nesting sites but several nesting seasons may be required to reach maximum encounter rate. Spatial analyses of nest location and nest searching paths should therefore be used to place future nesting mounds strategically, to reduce the risk of road mortality of females, and larger or more numerous mounds should be created to increase the probability that turtles searching for nesting sites will encounter them. Based on the analyses of our five criteria, artificial nesting mounds present a promising conservation tool for freshwater turtles.

\section{Acknowledgements}

Financial support was provided by Environment Canada's Habitat Stewardship Program, Ontario Ministry of Natural
Resources (OMNR) Species at Risk Stewardship Fund, Natural Sciences and Engineering Research Council of Canada (PGS-M Scholarship to JEP and Discovery Grant to JDL), and Laurentian University. Extensive in-kind contributions and financial support were provided by Algonquin Park (OMNR). Algonquin Forestry Authority constructed the artificial nesting mounds. E. Newton, E. Upham-Mills, M. McDermott, M. Keevil, A. Bennett, M. Rasmussen, E. Huner, T. Cameron, J. Riley and A. Leifso assisted in the field. All work was carried out under an approved Laurentian University Animal Care protocol and was authorized by permits from OMNR.

\section{References}

Aresco, M.J. (2005) The effect of sex-specific terrestrial movements and roads on the sex ratio of freshwater turtles. Biological

Conservation, 123, 37-44.

Arnold, C.Y. (1960) Maximum-minimum temperatures as a basis for computing heat units. Proceedings of the American Society of Horticultural Science, 76, 682-692.

Bakersville, G.L. \& Emin, P. (1969) Rapid estimation of heat accumulation from maximum and minimum temperatures. Ecology, 50, 514-517.

Beaudry, F., de Maynadier, P.G. \& Hunter, M.L. Jr (2010) Nesting movements and the use of anthropogenic nesting sites by spotted turtles (Clemmys guttata) and Blanding's turtles (Emydoidea blandingii). Herpetological Conservation and Biology, $5,1-8$.

Beyer, H.L. (2004) Hawth's Analysis Tools for ArcGIS. Http://www. spatialecology.com/htools [accessed 5 January 2009].

Bowne, D.R. \& White, H.R. (2004) Searching strategy of the painted turtle Chrysemys picta across spatial scales. Animal Behaviour, 68, 1401-1409.

Buhlmann, K.A. \& Osborn, C.P. (2011) Use of an artificial nesting mound by wood turtles (Glyptemys insculpta): a tool for turtle conservation. Northeastern Naturalist, $18,315-334$.

Burke, V.J., Rathbun, S.L., Bodie, J.R. \& Gibbons, J.W. (1998) Effect of density on predation rate for turtle nests in a complex landscape. Oikos, 83, 3-11.

Caldwell, I.R. \& Nams, V.O. (2006) A compass without a map: tortuosity and orientation of eastern painted turtles (Chrysemys picta picta) released in unfamiliar territory. Canadian Journal of Zoology, 84, 1129-1137.

Christens, E. \& Bider, J.R. (1987) Nesting activity and hatching success of the painted turtle (Chrysemys picta marginata) in southwestern Quebec. Herpetologica, 43, 55-65.

Compton, B.W., Rhymer, J.M. \& McCollough, M. (2002) Habitat selection by wood turtles (Clemmys insculpta): an application of paired logistic regression. Ecology, 83, 833-843.

Congdon, J.D., Breitenbach, G.L., van Loben Sels, R.C. \& TinkLe, D.W. (1987) Reproduction and nesting ecology of snapping turtles (Chelydra serpentina) in southeastern Michigan.

Herpetelogica, 43, 39-54.

De Solla, S.R., Fernie, K.J. \& Ashpole, S. (2008) Snapping turtles (Chelydra serpentina) as bioindicators in Canadian areas of concern in the Great Lakes Basin. II. Changes in hatching success and hatchling deformities in relation 
to persistent organic pollutants. Environmental Pollution, 153, 529-536.

Doody, J.S., Sims, R.A. \& Georges, A. (2003) Gregarious behavior of nesting turtles (Carettochelys insculpta) does not reduce predation risk. Copeia, 2003, 894-898.

Dowling, Z., Hartwig, T., Kiviat, E. \& Keesing, F. (2010) Experimental management of nesting habitat for the Blanding's turtle (Emyodidea blandingii). Ecological Restoration, 28, 154-159.

Draud, M., Bossert, M. \& Zimavoda, S. (2004) Predation on hatchling and juvenile diamondback terrapins (Malaclemys terrapin) by the Norway rat (Rattus norvegicus). Journal of Herpetology, 38, 467-470.

Edge, C.B., Steinberg, B.D., Brooks, R.J. \& Litzgus, J.D. (2010) Habitat selection by Blanding's turtles (Emydoidea blandingii) in a relatively pristine landscape. Écoscience, 17, 90-99.

Ernst, C.H. \& Lovich, J.E. (2009) Turtles of the United States and Canada, 2nd edition. Johns Hopkins University Press, Baltimore USA

Ewert, M.A. \& Nelson, C.E. (1991) Sex determination in turtles: diverse patterns and some possible adaptive values. Copeia, 1991, 50-69.

Freedberg, S., Ewert, M.A., Ridenhour, B.J., Neiman, M. \& Nelson, C.E. (2005) Nesting fidelity and molecular evidence for natal homing in the freshwater turtle, Graptemys kohnii. Proceedings of the Royal Society B, 272, 1345-1350.

GARCIA-BERTHOU, E. (2001) On the misuse of residuals in ecology: testing regression residuals vs. the analysis of covariance. Journal of Animal Ecology, 70, 708-711.

Gibions, J.W., Scott, D.E., Ryan, T.J., Buhlmann, K.A., Tuberville, T.D., Metts, B.S. et al. (2000) The global decline of reptiles, déjà vu amphibians. BioScience, 50, 653-666.

Gibis, J.P. \& Shriver, W.G. (2002) Estimating the effects of road mortality on turtle populations. Conservation Biology, 16, $1647-1652$.

Graham, T., Georges, A. \& McElhinney, N. (1996) Terrestrial orientation by the eastern long-necked turtle Chelodina longicollis, from Australia. Journal of Herpetology, 30, 467-477.

Gutzke, W.H.N., Packard, G.C., Packard, M.J. \& Boardman, T.J. (1987) Influence of the hydric and thermal environments on eggs and hatchlings of painted turtles (Chyrsemys picta). Herpetologica, 43, 393-404.

Haxton, T. (200o) Road mortality of snapping turtles, Chelydra serpentina, in central Ontario during their nesting period. The Canadian Field-Naturalist, 114, 106-110.

IUCN (2011) IUCN Red List of Threatened Species v. 2011.2. Http://www.iucnredlist.org [accessed 6 May 2012].

JАКОв, E.M., Marshall, S.D. \& UEтZ, G.W. (1996) Estimating fitness: a comparison of body condition indices. Oikos, 77, 61-67.

Janzen, F.J., Ast, J.C. \& Paukstis, G.L. (1995) Influence of the hydric environment and clutch on eggs and embryos of two sympatric map turtles. Functional Ecology, 9, 913-922.

Janzen, F.J., Tucker, J.K. \& Paukstis, G.L. (2000) Experimental analysis of an early life-history stage: selection on size of hatchling turtles. Ecology, 81, 2290-2304.

Kiviat, E., Stevens, G., Brauman, R., Hoeger, S., Petokas, P.J. \& Hollands, G.G. (2000) Restoration of wetland and upland habitat for the Blanding's turtle, Emydoidea blandingii. Chelonian Conservation and Biology, 3, 650-657.

Kolbe, J.J. \& Janzen, F.J. (2001) The influence of propagule size and maternal nest-site selection on survival and behavior in neonate turtles. Functional Ecology, 15, 772-781.
Kolbe, J.J. \& Janzen, F.J. (2002a) Impact of nest-site selection on nest success and nest temperature in natural and disturbed habitats. Ecology, 83, 269-281.

Kolbe, J.J. \& Janzen, F.J. (2002b) Experimental analysis of an early life-history stage: water loss and migrating hatchling turtles. Copeia, 2002, 220-226.

Kolbe, J.J. \& Janzen, F.J. (2002c) Spatial and temporal dynamics of turtle nest predation: edge effects. Oikos, 99, 538-544.

Litzgus, J.D., Bolton, F. \& Schulte-Hostedde, A.I. (2008) Reproductive output depends on body condition in spotted turtles (Clemmys guttata). Copeia, 2008, 86-92.

MarChand, M.N. \& Litvaitis, J.A. (2004a) Effects of habitat features and landscape composition on the population structure of a common aquatic turtle in a region undergoing rapid development. Conservation Biology, 18, 758-767.

Marchand, M.N. \& Litvaitis, J.A. (2004b) Effects of landscape composition, habitat features, and nest distribution on predation rates of simulated turtle nests. Biological Conservation, 117, 43-251.

Morjan, C.L. \& VAlenzuela, N. (2001) Is ground-nuzzling by female turtles associated with soil surface temperatures? Journal of Herpetology, 35, 668-672.

OвbаRD, M.E. \& Brooks, R.J. (1981) Fate of overwintered clutches of the common snapping turtle (Chelydra serpentina) in Algonquin Park, Ontario. The Canadian Field-Naturalist, 95, 350-352.

O'STEEN, S. (1998) Embryonic temperature influences juvenile temperature choice and growth rate in snapping turtles Chelydra serpentina. Journal of Experimental Biology, 201, 439-449.

Packard, G.C., Packard, M.J., Miller, K. \& Boardman, T.J. (1987) Influence of moisture, temperature, and substrate on snapping turtle eggs and embryos. Ecology, 68, 983-993.

Rasmussen, M.L. \& Litzgus, J.D. (2010) Patterns of maternal investment in spotted turtles (Clemmys guttata): implications of trade-offs, scales of analyses, and incubation substrates. Écoscience, $17,47-58$.

Rowe, J.W., Coval, K.A. \& Dugan, M.R. (2005) Nest placement, nest-site fidelity and nesting movements in midland painted turtles (Chrysemys picta marginata) on Beaver Island, Michigan. The American Midland Naturalist, 154, 383-397.

Samson, J., Hughes, E.J. \& Brooks, R.J. (2007) Excavation is a nondeleterious method for obtaining fecundity and morphometric data from small-sized eggs of freshwater turtles. Chelonian Conservation and Biology, 6, 255-259.

Schwarzkopf, L. \& Brooks, R.J. (1987) Nest-site selection and offspring sex ratio in painted turtles, Chrysemys picta. Copeia, 1987, 53-61.

Spencer, R. (2002) Experimentally testing nest site selection: fitness trade-offs and predation risk in turtles. Ecology, 83, 2136-2144.

Spencer, R. \& Thompson, M.B. (2003) The significance of predation in nest site selection of turtles: an experimental consideration of macro- and microhabitat preferences. Oikos, 102, 592-600

Standing, K.L., Herman, T.B. \& Morisson, I.P. (1999) Nesting ecology of Blanding's turtle (Emydoidea blandingii) in Nova Scotia, the northeastern limit of the species' range. Canadian Journal of Zoology, 77, 1609-1614.

Steen, D.A., Aresco, M.J., Beilke, S.G., Compton, B.W., Condon, E.P., Dodd, K.C. et al. (2006) Relative vulnerability of female turtles to road mortality. Animal Conservation, 9, 269-273.

Steen, D.A., Gibbs, J.P., Buhlmann, K.A., Carr, J.L., Compton, B.W., Congdon, J.D. et al. (2012) Terrestrial habitat requirements of nesting freshwater turtles. Biological Conservation, $150,121-128$. 
Steyermark, A.C. \& Spotila, J.R. (2001) Effects of maternal identity and incubation temperature on hatching and hatchling morphology in snapping turtles Chelydra serpentina. Copeia, 2001, 129-135.

Temple, S.A. (1987) Predation on turtle nests increases near ecological edges. Copeia, 1987, 250-252.

Walde, A.D., Bider, J.R., Masse, D., Saumure, R.A. \& Titman, R.D. (2007) Nesting ecology and hatching success of the wood turtle (Glyptemys insculpta), in Québec. Herpetological Conservation Biology, 2, 49-60.

WiLson, D.S. (1998) Nest-site selection: microhabitat variation and its effects on the survival of turtle embryos. Ecology, 79, 1884-1892.

\section{Biographical sketches}

JAMES E. PATERSON is interested in answering questions related to spatial ecology to improve conservation methods and in testing hypotheses about how animal populations use resources at different spatial and temporal scales. BRAD D. STEINBERG's research interests focus on the practical application of field data to the conservation and management of species at risk. JACQUeline D. LitzGus is interested in the life history, natural history, and physiological ecology of reptiles, and the application of these data to the recovery of species at risk. 